Manuscript type: Note

\title{
Versatile bridging ability of secondary thioamide group for constructing metal cluster based on pincer complex
}

Ken Okamoto, ${ }^{\mathrm{a}}$ Junpei Kuwabara, ${ }^{\mathrm{a}, \mathrm{b}}$ and Takaki Kanbara ${ }^{\mathrm{a}, \mathrm{b} *}$

${ }^{a}$ Tsukuba Research Center for Interdisciplinary Materials Science (TIMS), University of Tsukuba, 1-1-1 Tennodai, Tsukuba 305-8573, Japan.

${ }^{b}$ Graduate School of Pure and Applied Sciences, University of Tsukuba, 1-1-1 Tennodai, Tsukuba 305-8573, Japan.

RECEIVED DATE (to be automatically inserted after your manuscript is accepted if required according to the journal that you are submitting your paper to)

CORRESPONDING AUTHOR FOOTNOTE

Tsukuba Research Center for Interdisciplinary Materials Science (TIMS),

University of Tsukuba, 1-1-1 Tennodai, Tsukuba 305-8573, Japan.

E-mail: kanbara@ims.tsukuba.ac.jp;

FAX: $+81-29-853-4490$

TEL: +81-29-853-5066

\section{Abstract:}


The crystallization of SCS pincer platinum complex with secondary thioamide groups, [4methyl-2,6-bis(anilinothiocarbonyl)- $\kappa^{2} S, S^{\prime}$-phenyl- $\left.\kappa C^{1}\right]$ chloroplatinum(II), spontaneously forms trinuclear cluster complex accompanied by liberating $\mathrm{HCl}$ in $\mathrm{DMSO} / \mathrm{EtOH}$ mixture. The crystal structure of the SNS pincer copper complex with secondary thioamide groups, [2,5bis(benzylaminothiocarbonyl)- $\kappa^{2} S, S^{\prime}$-pyrrolyl- $\left.\kappa N^{1}\right]$ chlorocopper(II), exhibits a dimer structure bearing the bridging thioamide group. The thioamide group acts as the bridging ligand of the multimetallic complexes in different anionic and neutral manners.

Keywords: Secondary thioamide; Pincer ligand; Bridging ligand; Platinum complex; Copper complex

\section{Introduction}

Metal chalcogenido clusters are of great interest because of their unique electrical, magnetical, chemical, and catalytical properties [1]. Sulfur containing ligand such as thiols [2], thiosemicarbazone [3], and mercaptonicotinic acid [4] are often used as bridging ligands for constructing metal clusters due to their strong coordination property. However, the number of examples of thioamide-based metal clusters is limited. A thioamide group is one of the sulfurbased donating groups for constructing organometallic compounds [5-6]. Upon deprotonation, a secondary thioamide group forms thioamidate and iminothiolate as resonance structures (Scheme 1). The deprotonation gives a dramatically change in terms bridging ability of a thioamide group. Therefore, the secondary thioamide group serves as a bridging ligand in three manners such as neutral thioamide, thioamidate and iminothiolate. The versatility of the thioamide group as bridging ligand is expected to afford a new metal clusters. 
Pincer complexes generally have a tridentate ligand (ECE ligand) composed of a cyclometalating carbon and donating groups such as $\mathrm{PR}_{2}, \mathrm{NR}_{2}$ and $\mathrm{SR}$ [7]. The pincer complexes bearing thioamide groups as a donating group were also investigated [5]. Since the secondary thioamide group has potential for bridging the metal centers, the pincer complexes would assemble to form metal cluster based on pincer complexes. Herein, we report a formation of two kinds of cluster complexes from the monometallic pincer $\mathrm{Pt}$ and $\mathrm{Cu}$ complexes having the secondary thioamide moiety. The secondary thioamide group in each complex acts as a bridging ligand in different manners.

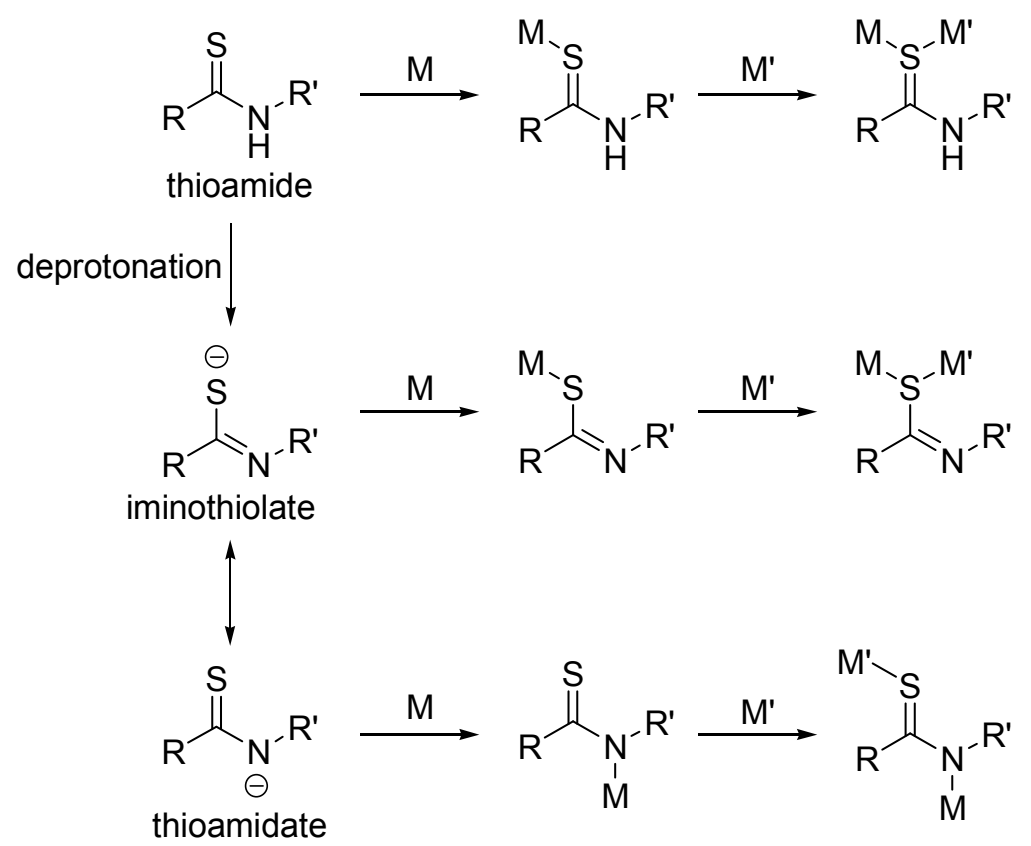

Scheme 1. The neutral and anionic forms of a secondary thioamide group and presumable coordination mode as a building block of metal clusters 


\section{Results and discussion}

\subsection{Synthesis and X-ray diffraction study of the trinuclear complex 2}

The Pt pincer complex 1 was prepared in accordance with the method in the previous report [5d]. The crystallization of $\mathbf{1}$ from DMSO gives single crystals having monometallic structure [5d]. In contrast, crystallization of $\mathbf{1}$ in a mixture of DMSO and EtOH gives different crystals having monoclinic lattice in $4 \%$ yield. The single X-ray diffractional analysis revealed the trimetallic structure as shown in Fig. 1. The chloride ligand on the Pt center and one of the proton in the N-H groups disappear in the trimetallic structure compared with the structure of the parent complex 1 (Scheme 1). These results indicate that $\mathrm{HCl}$ was liberated during the crystallization process. The deprotonation of the secondary thioamide group provides iminothiolate moieties bridging Pt centers.

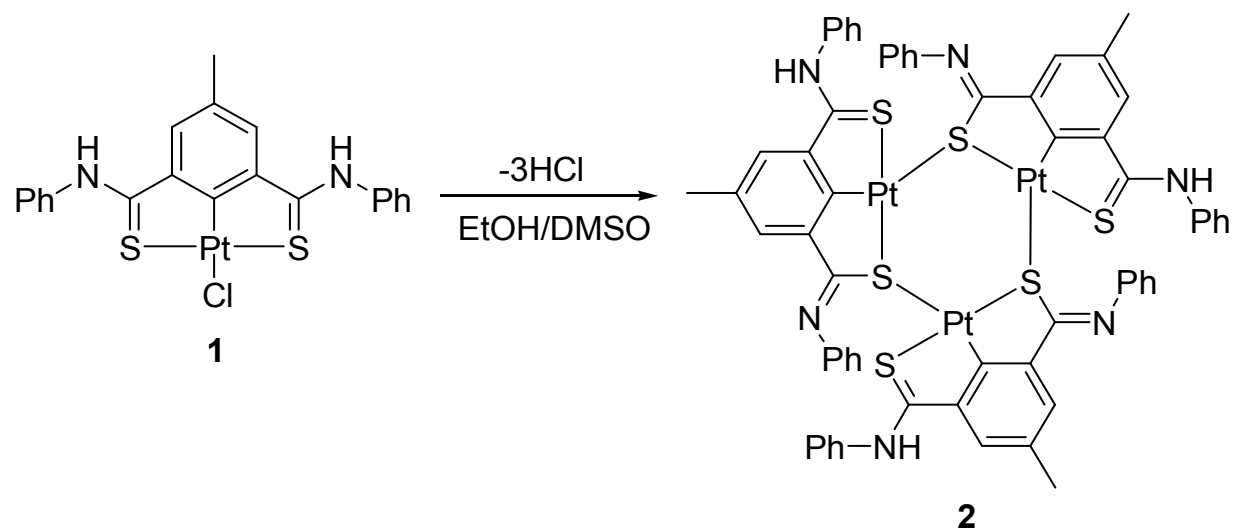

\section{Scheme 2.}

Since the total of the bond angles around the Pt centers are close to $360^{\circ}$, the each $\mathrm{Pt}$ center retains a distorted square planar structure in the trimetallic structure. The core of trimetallic cluster 2 consists of a six-membered ring of alternating Pt and S atoms (Fig. 1b). In terms of the lengths of six Pt-S bond in the six-membered ring, the Pt-S bonds in each SCS pincer structure is $2.304 \AA$ on average, which is shorter than the Pt-S bonds connecting each 
pincer complex (2.415 $\AA$ on average) (Table 1). The bond angles involving bridging sulfur atoms are as follows: Pt1-S2-Pt2, 88.79(10) ${ }^{\circ}$; Pt2-S3-Pt3, 98.92(9) ${ }^{\circ}$; Pt1-S5-Pt3, 100.45(10) ${ }^{\circ}$. The average bond distances between the carbon atom and the bridging $\mathrm{S}$ atom such as $\mathrm{S} 1-\mathrm{C} 2$ in cluster $\mathbf{2}$ is $1.823 \AA$, which is longer than the average of C-S bonds in parent complex $\mathbf{1}$ (1.707 $\AA$ ). These changes of bond lengths are consistent with formations of S-C single bonds of iminothiolate moieties in the cluster structure. In addition, the C-N distances of the iminothiolate moiety (1.261 $\AA$ on average) are shorter than those of the thioamide groups in complex $\mathbf{1}$ (1.318 $\AA)$ and $2(1.34 \AA)$ owing to a double bond character of the iminothiolate structure. The distances

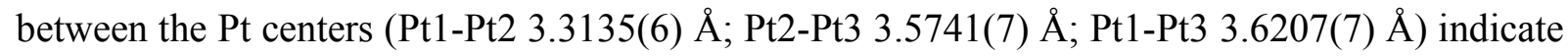
that there is no direct bond between the Pt atoms. Lei et al. reported SNS pincer Pd complexes having a centered 2,6-pyridine unit bearing secondary thioamide groups [8]; deprotonation of the secondary thioamide groups by strong base affords tetrametallic or trimetallic cluster depending on the substituent on thioamide group. The structure of the trimetallic cluster is similar to that of 2. In the case of these clusters, both of thioamide groups are deprotonated during the formation of the cluster because the SNS pincer ligand is neutral.

Fig. 1. 


\subsection{Detection of the intermediates for cluster 2 by MALDI-MS}

To obtain the information of the mechanism for the formation of cluster 2 , the intermediates of the reaction were detected by MALDI-MS. A portion of the solution for crystallization of 2 was taken out and measured MALDI-MS using dithranol as a matrix. Fig. 2 shows the spectrum of the molecular cations. The result exhibits the existence of monomer $(\mathrm{m} / \mathrm{z}$ $=555), \operatorname{dimer}(\mathrm{m} / \mathrm{z}=1111)$, trimer $(\mathrm{m} / \mathrm{z}=1665)$, tetramer $(\mathrm{m} / \mathrm{z}=2221)$, and pentamer $(\mathrm{m} / \mathrm{z}=$ 2276). This result indicates that the solution contains not only trimetallic complex observed by X-ray diffractional analysis but also the complexes with higher nuclearity. Since the ratio of the signal intensities of these complexes depends on the laser intensity for the acquisition of the spectrum, the laser partly breaks of the multimetallic complexes. From the mass spectra, most of thioamide groups in the complexes were deprotonated without an addition of base, which indicates that the liberation of $\mathrm{HCl}$ spontaneous occurs in a mixture of $\mathrm{EtOH}$ and DMSO. The unusual phenomena is presumably due to the thermodynamic stability of the multimetallic complexes. Since a solution of $\mathbf{1}$ in DMSO did not exhibit such liberation of $\mathrm{HCl}, \mathrm{EtOH}$ might induce a liberating $\mathrm{HCl}$ and the formation of cluster $\mathbf{2}$.

Fig. 2. 


\subsection{Synthesis and Crystal structure of the Cu complex 3}

To inquire the versatility of the secondary thioamide group as a bridging ligand, thioamide-based pincer ligand with a central pyrrole (SNS) was investigated. Crystallization of $\mathrm{Ni}$, Pd, and Pt complexes bearing the SNS pincer ligand gave single crystals having a monometallic structure [5c,5i]. In contrast, the copper complex bearing the SNS pincer ligand spontaneously forms a dimer structure with another kind of a bridging manner. The copper complex 3 was obtained in good yield (98\%) from the reaction of the SNS ligand and an equimolar amount of $\mathrm{CuCl}_{2}$ at room temperature. Complex $\mathbf{3}$ is fairly stable to air and water and shows good solubility in polar organic solvents such as acetone, EtOH, DMF, and DMSO. In contrast to the mass spectrometric analysis of the Pt complex, there is no significant peaks of a cluster complex in the spectrum for the solution of $\mathrm{Cu}$ complex 3 . However, crystal structure of the complex 3 exhibits dimer structure with the bridging neutral thioamide group (Fig. 3). Each copper(II) center has a $\kappa^{3} \mathrm{SNS}$ coordination of the pincer ligand. The coordination geometry around each metal center is a distorted square pyramidal, where the basal plane is defined by the pyrrolic $\mathrm{N}$ atom and the two $\mathrm{S}$ atoms of the pincer ligand, and the chloride ligand. Table 2 shows selected bond lengths and angles of complex 3. The apical position of the square pyramid is occupied by one of the sulfur atoms in the closest $\mathrm{Cu}$ complex. The basal planes of the bridged two square pyramid are parallel to each other. The $\mathrm{Cu}_{2}(\mu-\mathrm{S})_{2}$ core is parallelogram, with a Cu$(\mu-\mathrm{S})-\mathrm{Cu}$ angle of $93.45(3)^{\circ}$. The two $\mathrm{Cu}-\mathrm{S}_{\text {basal }}$ bond distances are 2.4137(11) $\AA$ and 2.3957(9) $\AA$, which are shorter than the $\mathrm{Cu}-\mathrm{S}_{\text {apical }}$ bond distance of 2.809(2) $\AA$. The unique structure is found only in a small number of $\mathrm{Cu}(\mathrm{II})$ pincer complexes [9] and this is the first example of a dimer structure of a neutral copper pincer complex. Fig. $3 \mathrm{~b}$ shows that the existence of an 
intermolecular $\mathrm{N}-\mathrm{H} \cdots \mathrm{Cl}$ hydrogen bond of dimer 3 resulting in the formation of a linear double chain network structure along the $a$ axis in the solid state.

Fig. 3.

\section{Conclusions}

In summary, we found versatility of a secondary thioamide group as a bridging ligand. The thioamide group of the SCS pincer Pt complex acts as the anionic bridging ligand in an iminothiolate form for the formation of the trimetallic cluster. On the other hand, copper complex with the SNS ligand forms dimer structure with the neutral thioamide group as a bridging ligand. These new findings provide a possibility of a thioamide group as a bridging block for metal chalcogenide clusters.

\section{Experimental}

\subsection{General Procedures}

Commercially available solvents were used for recrystallizations. $N, N^{\prime}$-dibenzyl-1H-pyrrole-2,5dicarbothioamide and Pt pincer complex 1 were prepared in accordance with the method in the previous report [5c,5d]. NMR spectra were recorded on a JEOL JNM-EX-400 NMR spectrometer. MALDI-TOF-MS analyses were performed by an AXIMA-CFR plus MALDITOF mass spectrometer (Shimadzu/Kratos) equipped with a pulse nitrogen laser operated at 337 nm. MALDI mass spectra were acquired in the linear mode under following parameters: ion 
source; $20 \mathrm{kV}$, lens; $6.5 \mathrm{kV}$, pulsed extraction; $-2.5 \mathrm{kV}$, reflection; $25 \mathrm{kV}$.[10] For preparing the samples, the solution of the complexes in DMSO and EtOH $(1 \mu \mathrm{L})$ was mixed with $3 \mu \mathrm{L}$ of matrix solution (using dithranol as a matrix). The mixture was spotted onto the MALDI sample plate and then evaporated under a gentle stream of air. For measurements, a total of 100 profiles (5 shots per profile) were accumulated by searching for 10-20 hot spots for the sample.

\subsection{Synthesis of trimetallic cluster 2}

The trinuclear complex was prepared by the crystallization of $\mathbf{1}$ form the mixture of DMSO and EtOH. The isolated yield of the crystals was $4 \%$.

Anal.Calcd for $\mathrm{C}_{63} \mathrm{H}_{48} \mathrm{~N}_{6} \mathrm{Pt}_{3} \mathrm{~S}_{6}$.DMSO: $\mathrm{C}, 44.74 ; \mathrm{H}, 3.12 ; \mathrm{N}, 4.82$. Found: $\mathrm{C}, 44.16 ; \mathrm{H}, 3.31 ; \mathrm{N}$, 4.55 .

\subsection{Synthesis of dimeric copper complex 3}

A mixture of $N, N^{\prime}$-dibenzyl-1H-pyrrole-2,5-dicarbothioamide (36 $\mathrm{mg}, 0.10 \mathrm{mmol}$ ) and $\mathrm{CuCl}_{2} \cdot 2 \mathrm{H}_{2} \mathrm{O}(17 \mathrm{mg}, 0.10 \mathrm{mmol})$ in ethanol $\left(5 \mathrm{~cm}^{3}\right)$ was stirred at room temperature for $10 \mathrm{~min}$. The reaction mixture was filtered and the filtrate was concentrated. Purification of the product was carried out by a recrystallization from acetone to give dark greenish crystals ( $45 \mathrm{mg}, 98 \%$ yield).

FAB-mass: $m / z=427[\mathrm{M}-\mathrm{Cl}]^{+}$. Anal.Calcd for $\mathrm{C}_{20} \mathrm{H}_{18} \mathrm{ClCuN}_{3} \mathrm{~S}_{2}: \mathrm{C}, 51.83 ; \mathrm{H}, 3.91 ; \mathrm{N}, 7.65$. Found: C, 51.43; H, 3.81; N, 7.35.

4.4 X-ray Crystallographic Study 
The diffraction data were collected with a Bruker-APEX-II CCD diffractometer and Rigaku Saturn CCD area detector with graphite monochromated $\operatorname{MoK\alpha }(\lambda=0.71070 \AA)$ at $-160{ }^{\circ} \mathrm{C}$. The data were corrected for Lorentz and polarization effects, and an empirical absorption correction was applied. The structure was solved by direct methods (SIR 2002) and expanded using Fourier techniques. The non-hydrogen atoms except for disordered atoms were refined anisotropically. In the refinement all hydrogen atoms were included using the riding model with temperature parameter factors. CCDC 794887 and 798285 contains the supplementary crystallographic data for complexes $\mathbf{2}$ and $\mathbf{3}$, respectively.

2-DMSO: $\mathrm{C}_{65} \mathrm{H}_{54} \mathrm{~N}_{6} \mathrm{Pt}_{3} \mathrm{~S}_{7} \mathrm{O}, M=1744.87$, monoclinic, space group $\mathrm{P} 21 / \mathrm{c}, a=9.7553(9)$, $b=22.401(2), c=26.879(2) \AA, \beta=99.976(2), V=5785.0(9) \AA^{3}, Z=4, D_{\text {calc }}=2.003 \mathrm{gcm}^{-3} . \mathrm{A}$ total of 34085 reflections were measured, 12880 unique. The final cycle of full-matrix least squares refinement on $F$ was based on 8847 observed reflections $(I>2.00 \sigma(I))$, with factors of $R_{1}$ $=0.0586, R_{w}=0.1500, \mathrm{GOF}=1.047$.

3: $\mathrm{C}_{20} \mathrm{H}_{18} \mathrm{ClCuN}_{3} \mathrm{~S}_{2}, M=463.50$, triclinic, space group P-1, $a=8.795(7), b=10.655(8), c$ $=11.048(9) \AA, \alpha=95.118(9), \beta=111.780(11), \gamma=95.122(9)^{\circ}, V=949.1(12) \AA^{3}, Z=2, D_{\text {calc }}=$ $1.622 \mathrm{gcm}^{-3}$. A total of 6604 reflections were measured, 3929 unique. The final cycle of fullmatrix least squares refinement on $F$ was based on 3541 observed reflections $(I>2.00 \sigma(I))$, with factors of $R_{1}=0.0513, R_{w}=0.0695, \mathrm{GOF}=0.955$

\section{Acknowledgements}

The authors are grateful to the Chemical Analysis Center of University of Tsukuba for elemental analyses and NMR spectroscopy. The authors are grateful to Dr. Jun-Chul Choi and 
Dr. Yasumasa Takenaka for the measurement and refinement of the crystal structure, and Dr. Katsuhiko Ariga and Dr. Jonathan P. Hill for the measurements of mass spectrometry. 
References

[1] (a) M. Moskovits, Metal Clusters, John Wiley \& Sons, New York, 1986;

(b) P. Braunstein, L.A. Oro, P.R. Raithby, Metal Clusters in Chemistry, Wiley-VCH, Weinheim, 1999;

(c) D.F. Shriver, H.D. Kaesz, R.D. Adams, The Chemistry of Metal Cluster Complexes, VCH Publishers. Inc.. New York. 1990:

(d) Y. Ohki, Y. Ikagawa, K. Tatsumi, J. Am. Chem. Soc. 129 (2007) 10457-10465.

[2] (a) C. Albrecht, S. Schwieger, C. Bruhn, C. Wagner, R. Kluge, H. Schmidt, D. Steinborn, J. Am. Chem. Soc. 129 (2007) 4551;

(b) N. Hadj-Bagheri, J. Browning, K. Dehghan, K.R. Dixon, N.J. Meanwell, R.Vefghi, J. Organomet. Chem. 396 (1990) C47.

[3] (a) P. Chellan, S. Nasser, L. Vivas, K. Chibale, G.S. Smith, J. Organomet. Chem. 695 (2010) 2225;

(b) A. Amoedo, L.A. Adrio, J.M. Antelo, J. Martínez, M.T. Pereira, A. Fernández, J.M. Vila, Eur. J. Inorg. Chem. (2006) 3016;

(c) J. Martínez, L.A. Adrio, J.M. Antelo, J.M. Ortigueira, M.T. Pereira, M. López-Torres, J.M. Vila, J. Organomet. Chem. 691 (2006) 2891;

(d) A.I. Matesanz, C. Pastor, P. Souza, Inorg. Chem. Comm. 10 (2007) 97;

(e) D. Kovala-Demertzi, N. Kourkoumelis, M.A. Demertzis, J.R. Miller, C.S. Frampton, J.K. Swearingen, D.X. West, Eur. J. Inorg. Chem. (2000) 727;

(f) M. Yasui, S. Yoshida, S. Kakuma, S. Shimamoto, N. Matsumura, F. Iwasaki, Bull. Chem. Soc. Jpn. 69 (1996) 2739;

(g) F. Iwasaki, N. Manabe, M. Yasui, N. Matsumura, N. Kamiya, H. Iwasaki, Bull. Chem. Soc. Jpn. 69 (1996) 2749;

(h) F. Iwasaki, M. Yasui, S. Yoshida, H. Nishiyama, S. Shimamoto, N. Matsumura, Bull. Chem. Soc. Jpn. 69 (1996) 2759.

[4] (a) S. Marchal, V. Moreno, G. Aullón, S. Alvarez, M. Quirós, M. Font-Bardia, X. Solans, Polyhedron 18 (1999) 3675;

(b) C. Vetter, C. Wagner, J. Schmidt, D. Steinborn, Inorg. Chim. Acta 359 (2006) 4326.

[5] (a) T. Kanbara, K. Okada, T. Yamamoto, H. Ogawa, T. Inoue, J. Organomet. Chem. 689 (2004) 1860;

(b) M. Akaiwa, T. Kanbara, H. Fukumoto, T. Yamamoto, J. Organomet. Chem. 690 (2005) 4192;

(c) K. Okamoto, T. Kanbara, T. Yamamoto, Chem. Lett. 35 (2006) 558.

(d) K. Okamoto, T. Kanbara, T. Yamamoto, A. Wada, Organometallics 25 (2006) 4026;

(e) K. Okamoto, T. Yamamoto, M. Akita, A. Wada, T. Kanbara, Organometallics 28 (2009) 3307 ;

(f) J. Kuwabara, T. Kanbara, J. Photopolym. Sci. Technol. 21 (2008) 349;

(g) K. Okamoto, T. Yamamoto, T. Kanbara, J. Nanosci. Nanotechnol. 9 (2009) 646;

(h) J. Kuwabara, G. Munezawa, K. Okamoto, T. Kanbara, Danlton Trans. 39 (2010) 6255;

(i) T. Koizumi, T. Teratani, K. Okamoto, T, Yamamoto, Y. Shimoi, T. Kanbara, Inorg. Chim. Acta 363 (2010) 2474.

[6] (a) M. A.Hossain, S.O.Kang, J. M.Llinares, D.Powell,K.Bowman-James, Inorg. Chem. 42 (2003) 5043;

(b) R.A. Begum, D. Powell, K. Bowman-James, Inorg. Chem. 45 (2006) 964;

(c)V.A. Kozlov, D.V. Aleksanyan, Y.V. Nelyubina, K.A. Lyssenko, E.I. Gutsul, L.N. Puntus, A.A. Vasil'ev, P.V. Petrovskii, I.L. Odinets, Organometallics 27 (2008) 4062. 
[7] (a) M. Albrecht, G. van Koten, Angew. Chem., Int. Ed. 40 (2001) 3750;

(b) J.T. Singleton, Tetrahedron 59 (2003) 1837;

(c) M.E. van der Boom, D. Milstein, Chem. Rev. 103 (2003) 1759;

(d) D. Pugh, A.A. Danopoulos, Coord. Chem. Rev. 251 (2007) 610.

[8] (a) H. Wang, J. Liu, Y. Deng, T. Min, G. Yu, X. Wu, Z. Yang, A. Lei, Chem. Eur. J. 15 (2009) 1499;

(b) J. Liu, H. Wang, H. Zhang, X. Wu,H. Zhang, Y. Deng, Z. Yang, A. Lei Chem. Eur. J. 15 (2009) 4437.

[9] R. Kapoor, A. Kataria, P. Venugopalan, P. Kapoor, M. Corbella, M. Rodriguez, I. Romero, A. Llobet, Inorg. Chem. 43 (2004) 6699.

[10] (a) K. Tanaka, K. Yoshino, Y. Naito, M. Toyoda, J. Mass Spectrom. Soc. Jpn. 56 (2008) 49;

(b) R. Abate, A. Ballistreri, G. Montaudo, D. Garozzo, G. Impallomeni, G. Critchley, K. Tanaka, Rapid Commun. Mass Spectrom. 7 (1993) 1033. 

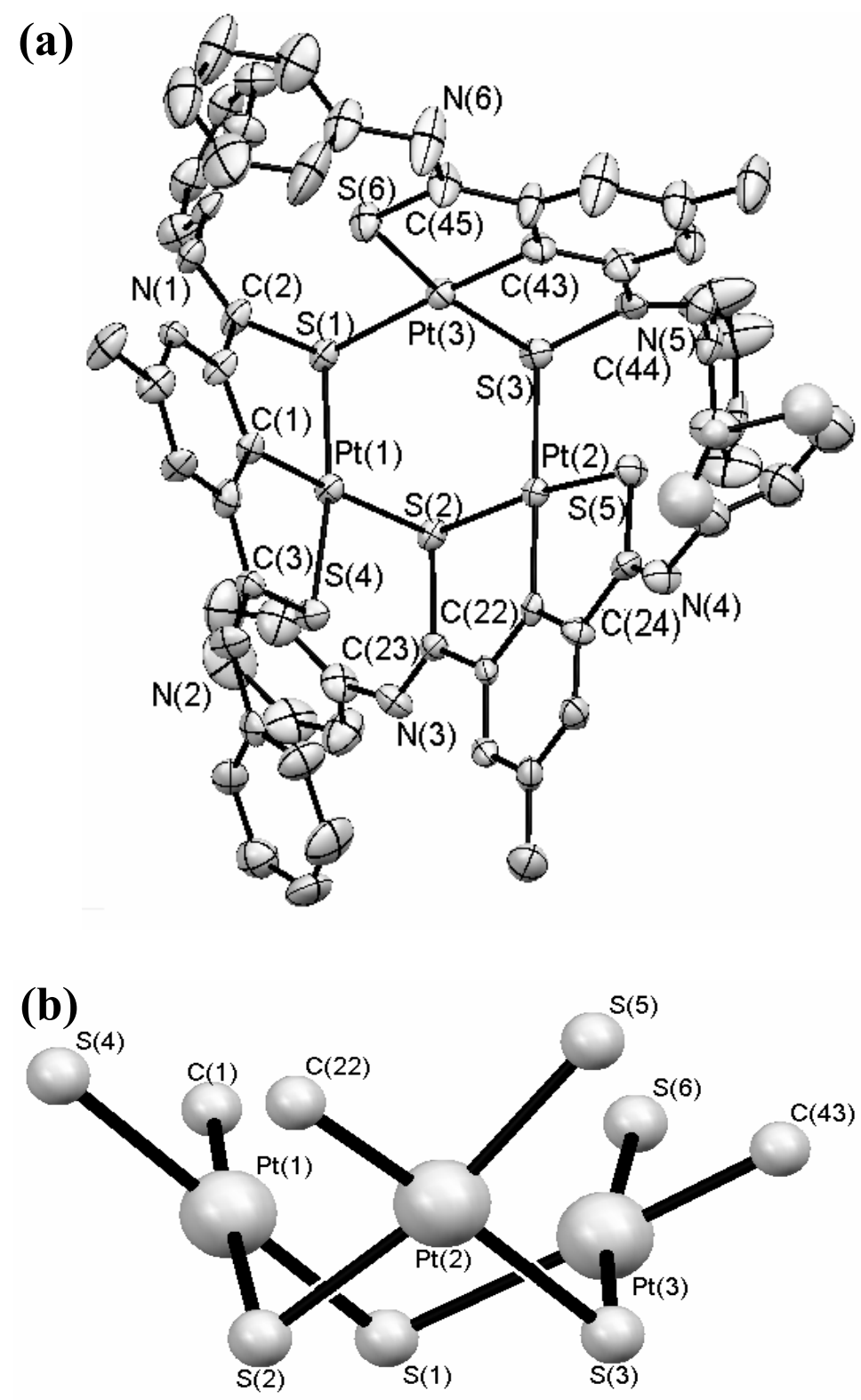

Fig. 1.(a) ORTEP drawing of 2 with thermal ellipsoids shown in 50\% probability level and (b) ball and stick model viewed along the $\mathrm{Pt}_{3} \mathrm{~S}_{3}$ core. Solvating molecules are omitted for clarity. 

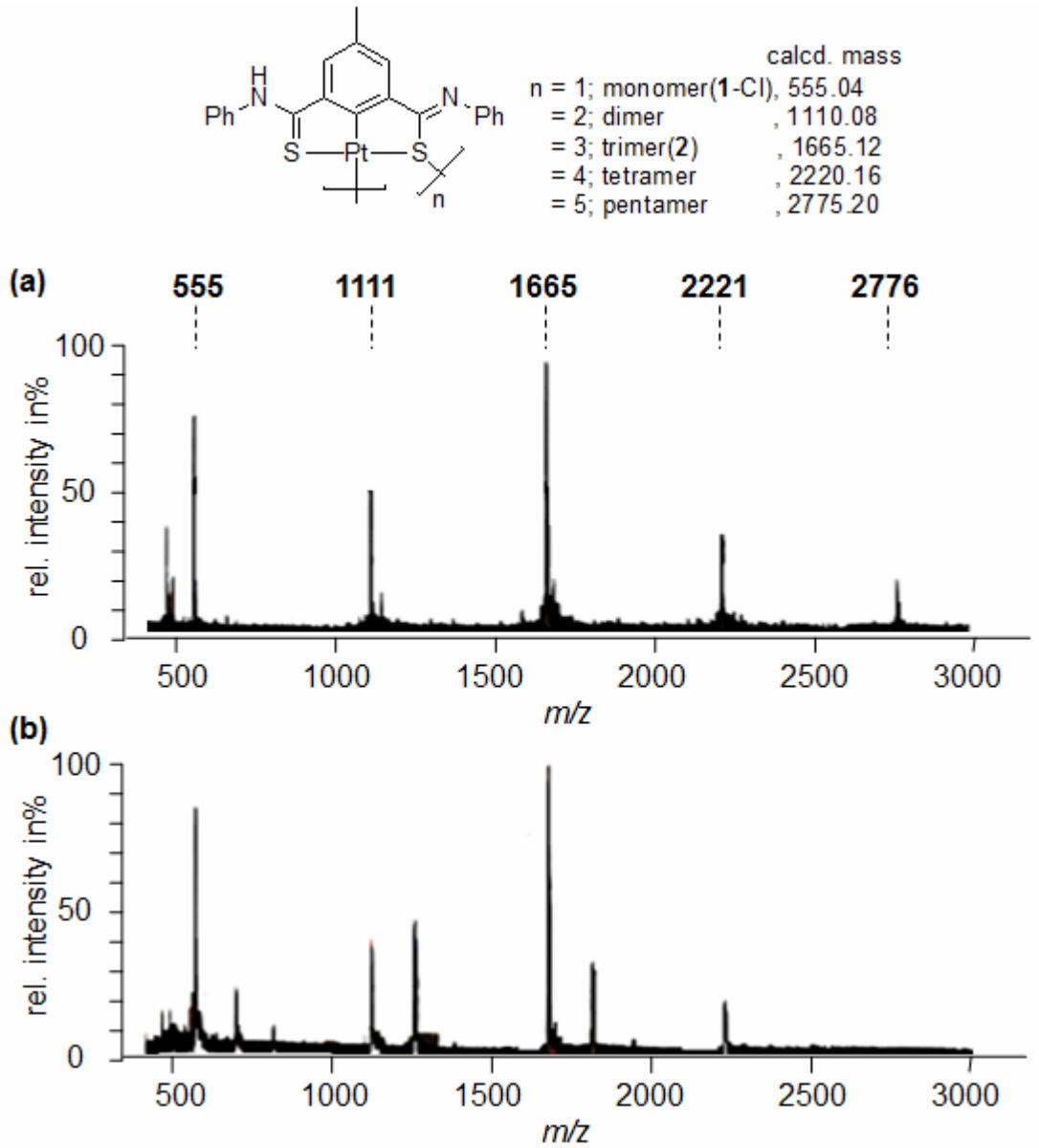

Fig. 2. Possible chemical structures and MALDI-mass spectrum from the solution of $\mathbf{1}$ in DMSO/EtOH with different laser intensity (a) laser power 70 and (b) laser power 90. 

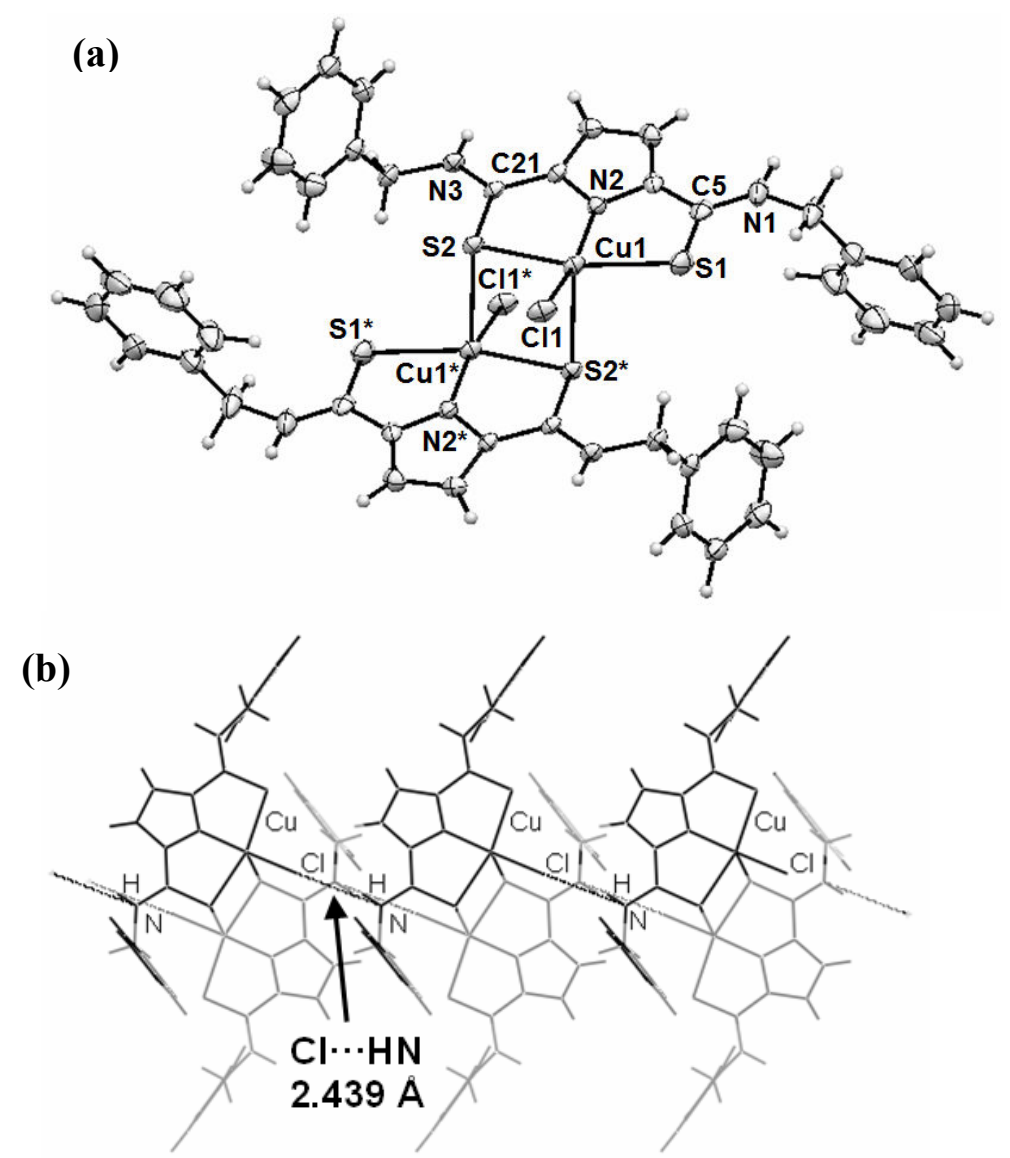

Fig.3. ORTEPdrawing of (a) dimer structure of $\mathbf{3}$ with thermal ellipsoids shown in $50 \%$ probability level, (b) a view of the extended network of the intermolecular hydrogen bonds in 3 . The $\mathrm{N}-\mathrm{H} \cdots \mathrm{Cl}$ hydrogen bonding distance is given in. 
Table 1. Selected bond length $(\AA)$ and angles (deg) for complexes $\mathbf{1}$ and $\mathbf{2}$

\begin{tabular}{|c|c|c|c|c|c|}
\hline \multicolumn{2}{|c|}{$1^{\mathrm{a}}$} & \multicolumn{4}{|c|}{2} \\
\hline \multirow[t]{3}{*}{ Pt1-C2 } & $1.957(7)$ & Pt1-C1 & $1.992(11)$ & Pt1-S1 & $2.310(2)$ \\
\hline & & $\mathrm{Pt} 2-\mathrm{C} 22$ & $1.985(10)$ & Pt1-S2 & $2.440(2)$ \\
\hline & & Pt3-C43 & $1.968(13)$ & Pt1-S4 & $2.292(2)$ \\
\hline $\mathrm{S} 1-\mathrm{C} 8^{b}$ & $1.700(7)$ & $\mathrm{S} 1-\mathrm{C} 2^{c}$ & $1.815(12)$ & $\mathrm{Pt} 2-\mathrm{S} 2$ & $2.293(2)$ \\
\hline \multirow[t]{5}{*}{$\mathrm{S} 2-\mathrm{C} 15^{b}$} & $1.714(7)$ & $\mathrm{S} 2-\mathrm{C} 23^{c}$ & $1.821(11)$ & $\mathrm{Pt} 2-\mathrm{S} 3$ & $2.401(2)$ \\
\hline & & $\mathrm{S} 3-\mathrm{C} 44^{c}$ & $1.833(13)$ & $\mathrm{Pt} 2-\mathrm{S} 5$ & $2.292(3)$ \\
\hline & & $\mathrm{S} 4-\mathrm{C} 3^{b}$ & $1.724(12)$ & $\mathrm{Pt} 3-\mathrm{S} 1$ & $2.401(2)$ \\
\hline & & S5-C2 $4^{b}$ & $1.712(12)$ & $\mathrm{Pt} 3-\mathrm{S} 3$ & $2.301(3)$ \\
\hline & & $\mathrm{S} 6-\mathrm{C} 45^{b}$ & $1.690(14)$ & $\mathrm{Pt3}-\mathrm{S} 6$ & $2.289(3)$ \\
\hline $\mathrm{N} 1-\mathrm{C} 8^{b}$ & $1.328(8)$ & $\mathrm{N} 1-\mathrm{C} 2^{c}$ & $1.256(15)$ & & \\
\hline \multirow[t]{5}{*}{$\mathrm{N} 2-\mathrm{C} 15^{b}$} & $1.307(8)$ & $\mathrm{N} 2-\mathrm{C} 3^{b}$ & $1.348(13)$ & & \\
\hline & & $\mathrm{N} 3-\mathrm{C} 23^{c}$ & $1.274(16)$ & & \\
\hline & & $\mathrm{N} 4-\mathrm{C} 24^{b}$ & $1.328(17)$ & & \\
\hline & & $\mathrm{N} 5-\mathrm{C} 44^{c}$ & $1.252(15)$ & & \\
\hline & & $\mathrm{N} 6-\mathrm{C} 45^{b}$ & $1.35(2)$ & & \\
\hline \multirow[t]{9}{*}{ S1-Pt1-S2 } & $170.77(6)$ & S1-Pt1-S4 & $169.06(10)$ & $\mathrm{S} 1-\mathrm{Pt} 1-\mathrm{S} 2$ & $93.36(9)$ \\
\hline & & $\mathrm{S} 2-\mathrm{Pt} 2-\mathrm{S} 5$ & $169.60(9)$ & $\mathrm{S} 2-\mathrm{Pt1}-\mathrm{S} 4$ & $97.24(10)$ \\
\hline & & S3-Pt3-S6 & 169.99(11) & $\mathrm{S} 2-\mathrm{Pt} 2-\mathrm{S} 3$ & $92.23(10)$ \\
\hline & & S1-Pt1-C1 & $85.6(3)$ & $\mathrm{S} 3-\mathrm{Pt} 2-\mathrm{S} 5$ & $97.47(10)$ \\
\hline & & S4-Pt1-C1 & $83.9(3)$ & S1-Pt3-S3 & $93.28(10)$ \\
\hline & & S2-Pt2-C22 & $85.2(3)$ & S1-Pt3-S6 & $96.71(11)$ \\
\hline & & S5-Pt2-C22 & $85.2(3)$ & & \\
\hline & & S3-Pt3-C43 & $85.4(4)$ & & \\
\hline & & S6-Pt3-C43 & $84.6(4)$ & & \\
\hline
\end{tabular}




\begin{tabular}{cccc}
\hline \multicolumn{4}{c}{ Table 2. Selected bond lengths $(\AA)$ and angles $(\mathrm{deg})$ for complex $\mathbf{3}$} \\
\hline $\mathrm{Cu} 1-\mathrm{N} 1$ & $1.885(3)$ & $\mathrm{S} 1-\mathrm{C} 5$ & $1.711(4)$ \\
$\mathrm{Cu} 1-\mathrm{S} 1$ & $2.4137(11)$ & $\mathrm{S} 2-\mathrm{C} 21$ & $1.716(4)$ \\
$\mathrm{Cu} 1-\mathrm{S} 2$ & $2.3957(9)$ & $\mathrm{N} 1-\mathrm{C} 5$ & $1.323(5)$ \\
$\mathrm{Cu} 1-\mathrm{Cl}$ & $2.2209(11)$ & $\mathrm{N} 3-\mathrm{C} 21$ & $1.315(4)$ \\
$\mathrm{N} 2-\mathrm{Cu} 1-\mathrm{S} 1$ & $82.36(8)$ & $\mathrm{S} 1-\mathrm{Cu} 1-\mathrm{C} 11$ & $97.98(3)$ \\
N2-Cu1-S2 & $83.24(8)$ & $\mathrm{S} 2-\mathrm{Cu} 1-\mathrm{Cl} 1$ & $94.88(3)$ \\
$\mathrm{N} 2-\mathrm{Cu}-\mathrm{C} 11$ & $162.67(8)$ & $\mathrm{S} 1-\mathrm{Cu} 1-\mathrm{S} 2$ & $165.29(4)$ \\
\hline
\end{tabular}

